\title{
LA MUJER NATURAL: LA INFLUENCIA DE CHARLES BAUDELAIRE EN L'AUTOMNE À PÉKIN DE BORIS VIAN
}

\author{
THE NATURAL WOMAN: THE INFLUENCE OF CHARLES \\ BAUDELAIRE IN BORIS VIAN'S L'AUTOMNE À PÉKIN
}

Mariana DE CABO

Universidad Católica Argentina

Universidad de Bourgogne Franche-Comté

Estefanía MONTECCHIO

Universidad Católica Argentina

Consejo Nacional de Investigaciones Científicas y Técnicas (CONICET)

Resumen: En un epígrafe de L'automne à Pékin (1947), Vian cita un fragmento de Fusées de Baudelaire: «Aimer une femme intelligente est un plaisir de pédéraste». En la cosmovisión de Baudelaire, la mujer, ser puramente natural, conduce al hombre a sus más bajos instintos y, en consecuencia, al mal. Por eso, la relación amorosa con el sexo femenino representa un acto sádico y primitivo entre una víctima y un victimario. Nos proponemos analizar, a partir del estudio de la concepción baudelairiana de la mujer, por qué Vian cita al escritor del siglo XIX y en qué medida este intertexto le permite moldear en su novela una presunta visión estereotipada del género femenino.

Palabras clave: Vian; Baudelaire; mujer; estereotipo; Literatura francesa

Abstract: In an epigraph from L'automne à Pékin (1947), Vian quotes a passage from Baudelaire's Fusées: «Aimer une femme intelligente est un plaisir de pédéraste». In Baudelaire's world view, the woman, a purely natural being, guides the man to his lowest instincts and, therefore, to evil. For that reason, the loving relationship with female represents a sadistic and primitive act between a victim and a killer. Our aim is to analyze, based on the baudelairean conception of women, the motive why Vian quotes the XIX ${ }^{\text {th }}$ century writer and how much this intertext allows Vian to shape in his novel a presumed stereotyped vision of the feminine gender.

Key words: Vian; Baudelaire; woman; stereotype; French Literature 

asi un siglo exacto media entre el nacimiento de Baudelaire (1821) y el de Vian (1920). Medio siglo, en cambio, entre Fusées (1897) y L'automne à Pékin (1947). Para esta última novela, cuyos epígrafes suelen no guardar relación con el contenido del capítulo1, el patafísico escogió una cita del poeta maldito que, en efecto, viene al caso: «aimer une femme intelligente est un plaisir de pédéraste» (Baudelaire en Vian, 1947: 261). Y es precisamente en el último movimiento del capítulo IX cuando se alcanza el clímax de objetivación de la mujer. ¿Qué influencia ejerce, entonces, Charles Baudelaire sobre la construcción de la mujer en Boris Vian, a quien se ha tildado de pornógrafo y misógino? El presente artículo se propone analizar en qué medida la cosmovisión baudelairiana incide en Vian para plasmar en sus textos una imagen supuestamente estereotipada del género femenino.

Con ese fin, partiremos de la concepción baudelairiana acerca de la naturaleza, a la que el poète maudit asocia con la figura de la mujer. Luego, profundizaremos el vínculo de dicha figura con el sadismo. Finalmente, indagaremos la construcción que Vian realiza de la mujer para analizar el propósito con el cual cita a Baudelaire.

\section{Baudelaire}

\section{1. Naturaleza caída / mujer natural}

Como señala Antoine Compagnon (2005: 104), frente a la violencia de la revolución, el antimodernista $^{2}$ retoma la noción del pecado original, esto es, la idea de un mundo dominado irremediable y permanentemente por el pecado, la culpa y el mal. Su objetivo radica en rebajar el optimismo y el progresismo de los modernistas al enaltecer la condición pecadora del hombre y el poder de la providencia sobre la libertad humana (Compagnon, 2005: 90). Por su parte, Baudelaire (1976: 715) observa que la mayor parte de los errores relativos a la belleza nacen de la falsa concepción del siglo XIX sobre la moral. La naturaleza fue tomada en este tiempo como fuente y modelo de todo lo bueno y bello posible. La negación del pecado original constituyó, prácticamente, la consecuencia del enceguecimiento general de esa época. Por consiguiente, Baudelaire, en su carácter antimodernista, expone una visión negativa de la naturaleza, ya que esta nos conduce a los impulsos más bajos. Tal como sostiene nuestro autor en Notes nouvelles sur Edgar Poe, la naturaleza no genera más que monstruos (Baudelaire, 1976: 325). Esto implica que el hombre no tiene posibilidad de progreso. Más bien, como indica en Fusées, el ser humano permanece siempre en estado salvaje (Baudelaire, 1975:

\footnotetext{
1 Efectivamente, muchos de los epígrafes de esta novela particular fueron extraídos de catálogos de Philips. Este hecho vuelve aún más significativa la elección de la cita de Baudelaire, que sí se relaciona con los sucesos del capítulo en cuestión. ${ }^{2}$ Según Compagnon, los antimodernistas son los verdaderos modernos, ya que se oponen a los ideales de la Modernidad, pero a la vez muestran gran interés y forman parte de todo lo vinculado al progreso (por ejemplo, la ambigua relación de Baudelaire con la fotografía).
} 
663). En este sentido, se opone a la visión positivista de la época, que cree plenamente en la evolución de la humanidad. Baudelaire comparte con su contemporáneo Ferdinand Brunetière la idea de la moral como lo opuesto a la naturaleza y se inclina hacia la antropología de Hobbes o de Joseph de Maistre, en lugar de la de Rousseau (Compagnon, 2005: 84-88). Considera, entonces, que el mito del buen salvaje es falso (Compagnon, 2005: 22). Por el contrario, para el poeta, la figura teológica y religiosa del pecado original denunciaría el mal universal de lo real.

La idea de una irremediable naturaleza caída se relaciona con una cosmovisión dualista. Lloyd James Austin (1956: 130-133) puntualiza que la doctrina dualista, desde los orígenes del cristianismo, siempre ha fascinado a hombres sagaces, interesados por el problema del mal y su relación con la unidad de la realidad y con la imagen de un Dios benévolo y omnipotente. Según explica Austin, Baudelaire, cercano a la sensibilidad gnóstica, convierte a Dios en un ermitaño, en un ser atroz y aislado que, si se expresase ante sus creaturas, destruiría lo finito; en un ser que no necesita mostrarse para reinar. Sin embargo, como afirma Austin (1956: 130-133), la relación entre el escritor y los dualistas no abarca lo ritual, sino que se limita a lo espiritual, ya que probablemente Baudelaire no conoció profundamente el gnosticismo. Por eso, el dualismo disiente con Baudelaire en algunos temas, como la importancia de la divinidad de Cristo y la adjudicación de la responsabilidad del mal a un Demiurgo: Baudelaire no sigue a la figura de Cristo y culpa a Dios del mal. En consecuencia, la idea cristiana de la redención a través de la crucifixión de Jesús resulta imposible y el pecado no se absuelve (Austin, 1956: 130-133). Por otro lado, el poeta reafirma la figura prometeica y romántica del artista que arregla los errores del creador: mejora un universo que, aunque sea divino, resulta defectuoso (Austin, 1956: 176). De esta manera, la labor creadora de la imaginación artística se justifica a partir de la condición mala de la naturaleza humana y de la realidad.

Para Baudelaire, solo al constatar la experiencia de lo visible y próximo, se comprenderá que la naturaleza no contribuye en nada. Pues, gracias a lo natural, el hombre se limita a concretar sus necesidades básicas de supervivencia (comer, dormir, beber) y no eleva su alma al dominio del arte, de la imaginación, de lo artificial. Es más, según asevera, la naturaleza conduce al pobre por el camino del mal, lo impulsa a satisfacer sus deseos primarios a toda costa: «à tuer son semblable, à le manger, à le séquestrer, à le torturer ; car, sitôt que nous sortons de l'ordre des nécessités et des besoins pour entrer dans celui du luxe et des plaisirs, nous voyons que la nature ne peut conseiller que le crime» (Baudelaire, 1976: 715). Entre los proyectos de escritura del poeta reunidos en Nouvelles et romans, se encuentra una trama que testimonia la naturaleza caída del hombre: la historia de un hambriento que en la búsqueda de un alimento cae abatido por una multitud (Baudelaire, 1908: 406). El hambre, un impulso natural, conduce a la indiferencia y prueba la profunda corrupción de la humanidad. Otro ejemplo se halla entre la recopilación de bocetos de Fragments. La historia que Baudelaire (1908: 408409) proyecta, titulada «La fin du monde», trata sobre la recurrencia de los vicios del hombre tanto en el origen como en el fin: las rivalidades, las guerras, el odio y el gusto por la destrucción y la propiedad. De este modo, el poeta sintetiza el pecado original, la hipocresía del positivismo y la vanidad de la lucha política: 
Mon ivresse en 1848. De quelle nature était cette ivresse ? Goût de la vengeance. Plaisir naturel de la démolition. Ivresse littéraire ; souvenir des lectures.

Le 15 mai. Toujours le goût de la destruction. Goût légitime, si tout ce qui est naturel est légitime.

Les horreurs de Juin. Folie du peuple et folie de la bourgeoisie. Amour naturel du crime (Baudelaire, 1975: 679).

Por el contrario, de acuerdo con Baudelaire (1976: 716), mientras la naturaleza, la voz del egoísmo, aconseja el crimen, la buena filosofía y la religión impelen al hombre a cuidar a los padres pobres e inválidos. Es decir que solo la razón y el cálculo originan lo bello y noble, así como solo de la virtud surge lo artificial. Ergo, el mal se comete sin esfuerzo, naturalmente, pero el bien necesita del arte para nacer. Baudelaire señala que, a lo largo de la historia, se identifican diferentes signos de la nobleza inmaterial del hombre en su desprecio por lo real y en el gusto por lo artificial: las joyas, lo brilloso, «les plumages bariolés, les étoffes chatoyantes» (1976: 716). Asimismo, se observan pruebas de la desmoralización de la naturaleza: el reinado de Luis XV, un monarca que amó la naturaleza y, por lo tanto, sembró la barbarie y no la civilización (Baudelaire, 1976: 716). Los periódicos constituyen otro ejemplo del gusto de la humanidad por el crimen. Según Baudelaire, en sus páginas se descubren «signes de la perversité humaine» (1975: 705): guerras, robos, indecencia, torturas y crímenes de príncipes, de naciones y de particulares. No obstante, el poeta afirma que «c'est de ce dégoûtant apéritif que l'homme civilisé accompagne son repas de chaque matin» (Baudelaire, 1975: 706).

Si lo natural resulta abominable, lo artificial se convierte, en cambio, en una categoría estética de suma importancia para el poeta maldito, ya que se trata de una creación del Arte ajena a la Naturaleza (Gautier, 1868: 39). Por eso, André Ferran (1933: 70) afirma que el arte representa la continua corrección que el hombre hace de la naturaleza. El dandi, en cuanto artista, purifica la naturaleza retocándose y transformándose a sí mismo para potenciar su belleza. Es decir, gracias al artificio, la obra de arte del dandi resulta su propia persona: el maquillaje, la vestimenta, la toilette (Ferran, 1933: 70).

Este rechazo de Baudelaire a la naturaleza se percibe también en relación con la belleza de la mujer, lo opuesto a la figura del dandi. Si el dandi representa la «suprême incarnation de l'idée du beau transportée dans la vie matérielle» (Baudelaire, 1976: 326) y la magnificencia de lo artificial, la mujer solo encarna lo natural, lo abominable y lo vulgar. Así lo confiesa el poeta en Mon cœur mis a nu:

La femme a faim et elle veut manger. Soif, et elle veut boire.

Elle est en rut et elle veut être foutue.

Le beau mérite !

La femme est naturelle, c'est-à-dire abominable.

Aussi est-elle toujours vulgaire, c'est-à-dire le contraire du Dandy (Baudelaire, 1975: 677).

La mujer natural es abominable. Necesita, por ende, esconder los rastros de su atroz forma. La moda y el maquillaje constituyen los medios para lograr este encubrimiento. Según la concepción baudelairiana, la mujer y el vestido conforman una sola entidad (Baudelaire, 1976: 716-717), puesto que, mientras la naturaleza solo logra simplificar la belleza femenina, el artificio de la moda y del maquillaje la ennoblece. En este sentido, Baudelaire (1976: 716-717) sostiene que la moda, vivo 
síntoma del gusto por el ideal, cumple el deseo femenino de parecer un individuo mágico y sobrenatural, ya que diviniza su frágil belleza, la eleva sobre lo natural, hace desaparecer las marcas de la naturaleza y ejerce su influencia sobre el espíritu. Por ejemplo, por medio de polvos, se obtiene una unidad en el color de la piel que la asemeja a la estatua. Asimismo, por medio del negro artificial que rodea el ojo y del rojo que acentúa los pómulos, se la representa como portadora de «une vie surnaturelle et excessive» (Baudelaire, 1976: 716-717). Por este motivo, según el poeta, la mujer jamás debe esconder el maquillaje, sino mostrarlo; tampoco debe adorar la belleza natural ni competir con la juventud o embellecer la fealdad, pues la pintura de la cara en cuanto arte solo sirve a la belleza. A través de estos métodos artificiales, se logra disimular la condición natural y deleznable de la feminidad.

\section{2. El sadismo}

En Le sadisme de Baudelaire, Blin observa que el amor al prójimo es una quimera del cristianismo y que no se debe a la naturaleza. Esta afirmación ofrece como corolario la idea de que, si la mujer se identifica con lo natural, conduce al hombre a una relación sádica, que mucho dista de la amorosa. Mientras la reciprocidad conforma lo distintivo del amor, el sadismo persigue únicamente un uso instrumental del individuo. De este modo, queda al descubierto la realidad del acto sexual. En «L'Héautontimorouménos», el yo poético anuncia:

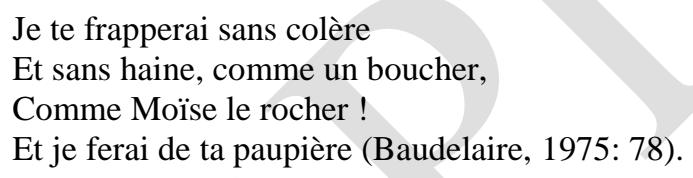

Como se observa a través de la imagen del yo lírico que golpea a la amada, en el erotismo de Baudelaire, la relación entre amante y amado se identifica con el vínculo entre víctima y victimario. El acto sexual se traduce en la idea de una tortura, de una operación quirúrgica. En «Le vampire», por ejemplo, el sujeto poético confiesa la sumisión a la que se encuentra obligada su alma a través de los versos:

Toi qui, comme un coup de couteau,

Dans mon cœur plaintif es entrée ;

Toi qui, forte comme un troupeau

De démons, vins, folle et parée,

De mon esprit humilié

Faire ton lit et ton domaine ;

- Infâme à qui je suis lié

Comme le forçat à la chaîne (Baudelaire, 1975: 33).

La mujer se presenta, así, asociada con la violencia (un coup de couteau) y lo demoníaco.

Blin añade que un instinto violento constituye el motor de la relación sexual. El comportamiento de la pareja reproduce un conflicto primitivo, que se caracteriza por la cólera y el miedo (Blin, 1948: 17-18). En el seno de este vínculo contradictorio de amor-violencia, se ubica el poema «A celle qui est 
trop gaie» que dedica Baudelaire (1975: 157) a Mme. Sabatier, y en el que exclama: «je te hais autant que je t'aime!». Postula, por lo tanto, la ligazón íntima entre la ferocidad y el amor (Baudelaire, 1975: 157). En «Une martyre» de Les Fleurs du Mal, el yo poético padece el irresistible influjo de una bella mujer decapitada:

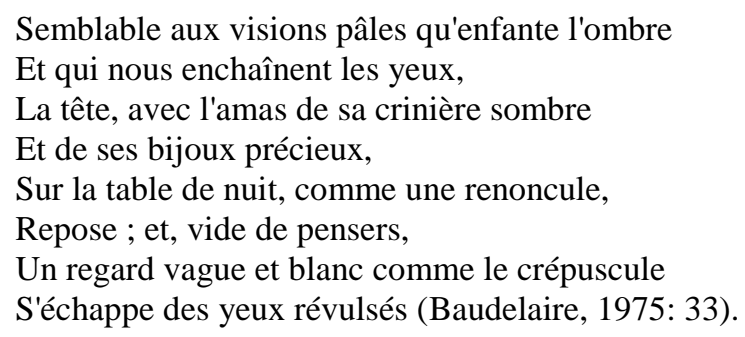

Sin embargo, apunta Blin que Baudelaire, a diferencia de Sade, se mantiene fiel a la tradición del bien. Por este motivo, busca romper con la naturaleza y corregirla (Blin, 1946: 48). En este sentido, pretende trascender el sadismo, en tanto Sade lo magnifica. La figura femenina, así, resulta un pretexto para reflejar su cosmovisión: un mundo naturalmente malo, que debe ser perfeccionado mediante el artificio.

La necesidad de perfeccionar la naturaleza caída se sintetiza en la dicotomía de la mujer salvaje y la mujer ideal. Según Debarati Sanyal (2014: 251), frente a la mujer puramente natural, se halla, en otros escritos, la mujer musa que inspira el arte puro y el ideal, y a quien Baudelaire dirige su obra. Se trata de una construcción femenina vacía que el poeta modela según su imaginación para la producción estética. En el seno de la modernidad, la mujer encarna la transición entre el simbolismo y el naturalismo: es materia y musa pasiva, organismo y metáfora, naturaleza y signo (Sanyal, 2014: 252). La presencia de la mujer natural en la poética baudelairiana no se reduciría a un simple desprecio, sino a una reflexión sobre el hacer poético: la mujer constituye la materia que trabajará la poesía para convertirla en figurativa. Para la postura filosófica baudelairiana de la condición caída de la naturaleza, la mujer puramente natural es demasiado fiel a lo real. De acuerdo con el poeta (Baudelaire, 1976: 715), el hombre no debe copiar la naturaleza corrupta, sino transformarla, perfeccionarla. No obstante, como sostiene Baudelaire, el siglo XIX, que niega el pecado original, sostiene que la naturaleza constituye la base, «source et type de tout bien et de tout beau posibles» (1976: 715).

La oposición entre naturaleza y artificio en Baudelaire resulta más compleja de lo que se suele pensar. Tal como señala Sanyal (2014: 255), en el poema en prosa «La femme sauvage et la petitemaîtresse», se cuestiona la distinción entre naturaleza y artificio, cuerpo y forma, materia y figura. La mujer idealizada, hostigada por el poeta, se opone a la mujer salvaje exhibida y torturada públicamente por su marido:

Vraiment, ma chère, vous me fatiguez sans mesure et sans pitié ; on dirait, à vous entendre soupirer, que vous souffrez plus que les glaneuses sexagénaires et que les vieilles mendiantes qui ramassent des croûtes de pain à la porte des cabarets.

[...] Faites bien attention ! Voyez avec quelle voracité (non simulée peut-être !) elle déchire des lapins vivants et des volailles piaillantes que lui jette son cornac. «Allons, dit-il, il ne faut pas manger tout son bien 
en un jour, » et, sur cette sage parole, il lui arrache cruellement la proie, dont les boyaux dévidés restent un instant accrochés aux dents de la bête féroce, de la femme, veux-je dire.

$[\ldots]$ Tant poète que je sois, je ne suis pas aussi dupe que vous voudriez le croire, et si vous me fatiguez trop souvent de vos précieuses pleurnicheries, je vous traiterai en femme sauvage, ou je vous jetterai par la fenêtre, comme une bouteille vide (Baudelaire, 1976: 289-290).

Este planteo se produce en el marco del poema en prosa, donde la poesía adquiere la materialidad de lo cotidiano. Como la mujer ideal se mezcla con la condición biológica de la mujer natural, la poesía adopta la materialidad de la prosa.

Para Sanyal, al deformar a estas figuras femeninas, Baudelaire muestra la violencia que genera la mujer en el seno del acto poético. Cuestiones estéticas sobre cómo aprehender la realidad o modificarla, o cuestiones ideológicas como el control de la mujer en el seno familiar son introducidas a través de este tópico que enlaza la mujer y la violencia. El poeta utiliza la imagen femenina para analizar la creación de la obra de arte en la modernidad (Sanyal, 2014: 252). La oposición entre la musa pasiva y la figura femenina natural simboliza el problema estético de la obra baudelairiana. Más allá de la impresión de misoginia que pueda provocar el poeta, la mujer constituye un instrumento para que Baudelaire desarrolle la cuestión de la imaginación y de la realidad en la era moderna. ¿Cómo concibe el escritor su obra de arte? ¿Relabora a través de la imaginación una imagen idealizada de la mujer o copia con fidelidad la naturaleza de la mujer? En ese sentido, deberíamos interpretar en tanto fuerza perturbadora que desata el enigma de la mujer en la obra de arte (Sanyal, 2014: 260) la brutal frase que reproduce Vian.

\section{Vian}

\section{1. La recepción de Vian como escritor misógino}

Las acusaciones de misoginia dirigidas a Vian se remontan a un texto de finales de 1946 (fecha no muy distante a la publicación del libro que nos concierne ${ }^{3}$ ): J'irai cracher sur vos tombes, roman publicado bajo el pseudónimo de Vernon Sullivan por las Éditions du Scorpion. Presentado como un policial negro, con sobrecubierta blanca al estilo Gallimard (Julliard, 1947: 138), esta obra ganó pronto el mote de succès de scandale (Scott, 1998: 17). Relata Clouzet que la novela proyectó un doble escándalo, el primero de los cuales se relacionaba con cuestiones morales:

Algunos lectores, desconcertados por las osadías eróticas — pornográficas, según ellos- del autor, tomaron la actitud de defensores de la moral. Los más apasionados de estos protestatarios encontraron un insólito abanderado en la persona de un cierto Daniel Parker [...], quien, pretendiendo actuar en nombre del «Cartel de Acción Moral», llevó su resentimiento hasta el extremo de perseguir judicialmente a Vernon Sullivan. [...] Durante muchos meses, los seguidores de Daniel Parker se comportaron como si Vian, perdón, Sullivan, los hubiera ofendido o puesto en entredicho personalmente. En varias ocasiones fueron a manifestarse bajo sus ventanas, lo insultaron en público y en cartas enviadas a los principales periódicos. La justicia intervino [...] y casi cuatro años después de la aparición de Escupiré sobre vuestras tumbas, el autortraductor y el editor fueron condenados a pagar 100.000 francos de multa por «ultraje escrito a la moral y a las buenas costumbres» (1971: 28-29).

\footnotetext{
${ }^{3}$ Vian comenzó la redacción de L'automne à Pékin a fines de 1946, pero publicó la novela al año siguiente.
} 
El alegato utilizado por el censor para quitar la obra de la vista del público lector («puede incitar a actos de exceso y sadismo») constituye un cliché que significativamente hace eco de un lugar común denunciado por Flaubert: «NOVELAS. Pervierten a las masas» (Flaubert, 2004: 73)4. En lugar de alejar el texto del público, esta disputa tan solo contribuyó a popularizar la nouvelle, que «se vende, de un día para otro, a carretadas» (Arnaud, 1990: 82). Vian mismo se burla de este hecho en su ensayo intitulado «Utilité d'une littérature érotique», en el que asevera: «et puisque j'ai nommé Daniel Parker, je dois reconnaître que peu des gens ont fait plus que lui pour la diffusion des ouvrages à caractère particulier...» (Vian, 1998: 44).

De cualquier modo, cabe destacar las palabras de Arnaud, que, al referirse a J'irai cracher sur vos tombes, observa que si bien «la reivindicación antirracista no está ausente — ni mucho menosde la novela, se ve dominada, y ahogada por así decirlo, por la sexualidad» (1990: 87).

Esta fama de pornógrafo lo persiguió a tal punto que fue cuestionada su seriedad como artista, bajo el argumento de la responsabilidad moral que un autor debe asumir por su obra (Scott, 1998: 23).

Pese a estas acusaciones, resulta llamativo que el «maître pornographe, [...] interdit, $[\ldots]$ condamné pour outrage aux mœurs par la voie du libre, $[. .$.$] monstre de perversité menant à sa perte$ la jeunesse sale et débraillé d'hier» (Arnaud en Vian, 1998: 7) haya mantenido inéditos sus Écrits pornographiques (Arnaud en Vian, 1998: 8). Es más, Arnaud afirma que se trataba de un ejercicio que prefería dejar a los especialistas (en Vian, 1998: 10). Pareciera que, tras haber sido catalogado como tal, Vian hubiera decidido s'encanailler: asumir esa fama de pornógrafo que se le endilgó a través de la escritura de unos textos pornográficos.

Sin embargo, detrás de la presentación de J'irai cracher sur vos tombes en tanto novela negra, que implicaba la adopción de sus códigos en lo que concierne tanto a lo textual como a lo paratextual, ¿no podría estar ocultándose otro nivel de lectura? Así lo sostiene Schoolcraft, para quien «si un canular offre ce à quoi le public s'attend, n'est-ce pas pour mieux le piéger tout en se réservant la possibilité d'y dissimuler un autre sens?» (Schoolcraft, 2009: 67). Pestureau se manifiesta afín a esta idea al aseverar que «la connaissance de la littérature américaine, au sens large, a aidé Vian à transgresser toutes les barrières qui existaient en France, quant au [sic] diverses catégories de livre» (Pestureau en Scott, 1998: 134). En definitiva, como sostiene Scott, dicha elección le permitió incursionar en la variedad de los géneros literarios, pero además tratar cuestiones impensables en la ficción francesa contemporánea (Scott, 1998: 215). Dicha afirmación se reproduce, aunque de manera un poco más amplia, en lo señalado por Schoolcraft, para quien Vian,

[...] en effet, remet en question toutes sortes de genres: genres littéraires et musicaux, mais également genres sexuels et, puisqu'on parle du genre humain, catégories raciales. Deux lignes d'attaque majeures donc, l'une sociale, l'autre esthétique. (2009: 61)

Por otra parte, el concepto de écrivain engagé, contemporáneo a nuestro escritor, promovía el abordaje de cuestiones controvertidas desde los géneros literarios mayores. Y, por el contrario,

4 Este hecho resulta significativo en la medida en que, según sostenemos, los escritores en cuestión están luchando contra la doxa de la sociedad francesa, cuyos clichés fueron recopilados por Flaubert en su Dictionnaire des idées reçues. 
[...] Vian cherchait un moyen de parler sans se plier au code de l'auteur engagé et responsable. En empruntant les doubles voies du roman noir et du canular, Vian s'est donné deux mauvais genres à la mode pour dissimuler une intervention dans des débats qui lui tenaient à cœur. (Schwitzer en Schoolcraft, 2009: 70)

Ciertamente, nadie espera que un género menor se ocupe de temas serios. Recién tres años después de la publicación de estos textos, Simone de Beauvoir ofrecería «l'ouvrage inaugural du féminisme contemporain» (Winock, 1997: 448): Le Deuxième Sexe, texto ensayístico - y como tal, de tono grave- cuyas páginas iniciales fueron publicadas en primera instancia en Les Temps Modernes, la institución intelectual de la época. Vian podría resultar un precursor que se vale del marco genérico ofrecido por el canular como un medio para escapar de la censura. Pues, ¿cómo era vista la sexualidad en la sociedad francesa de aquella época? Según Winock, «on s'en étonne aujourd'hui tant cette époque prude, innocente ou hypocrite, semble éloignée», ya que «les Français ne parlaient du sexe que sous le forme de la gaudriole ou de la sublimation» (Winock, 1997: 444). Tal es así que «les médecins eux-mêmes, en tout cas la majorité d'entre eux, s'interdisaient avec leurs patientes tout vocabulaire réaliste ou scientifique. Le sexe restait matière à allusions, à fascination secrète, à comédies de boulevard et à journaux polissons» (Winock, 1997: 445). Tampoco debe olvidarse, al respecto, que «les stéréotypes sont une contrainte du (mauvais) genre, sa matière même» (Schoolcraft, 2009: 67). Vian contaba con este argumento a su favor. Las palabras del mismo Vian en «Utilité d'une littérature érotique» servirían para reforzar esta hipótesis acerca del uso de este género menor para huir de los censores en el abordaje de semejante temática escandalosa: «Colette fut assez habile pour présenter son œuvre sous une apparence peu susceptible d'attirer l'œil des censeurs» (Vian, 1998: 47). Por consiguiente, nuestro autor recurre a la novela negra y a sus estereotipos para denunciarlos. Sin embargo, esta operación que realiza bajo la máscara de Vernon Sullivan, no es exclusiva del ciclo de novelas publicadas bajo el pseudónimo Vernon Sullivan (J'irai cracher sur vos tombes [1946], Les morts ont tous la même peau [1947], Et on tuera tous les affreux [1948], Elles se rendent pas compte $[1950])^{5}$.

\section{2. Representación estereotipada de la figura femenina en $L$ 'automne à Pékin}

Tal como acabamos de adelantar, una mujer ideal aparece representada, tanto en las obras «serias» y en las «no serias», como el androide, «féminité pure débarrassée d'encombrantes fonctions» (Duchateau, 1982: 30). La figura femenina es tratada como objeto y es posible inferir este hecho a partir de las descripciones de los diversos personajes femeninos.

Cabe destacar que, en este artículo, nos centraremos únicamente en Rochelle de L'automne à Pékin, ya que se trata del personaje implicado en el movimiento al que pertenece el epígrafe de Baudelaire. Para realizar este estudio, nos valdremos de los análisis realizados por Rybalka y Rolls. El

\footnotetext{
${ }^{5}$ En oposición a las novelas de Sullivan, la recepción crítica de sus contemporáneos, tal como lo exponen Clouzet (1976), Arnaud (1990) y Scott (1998), muestran implícitamente la distancia que había entre Vernon y Boris. Se definieron como «obras serias»: Trouble dans les andains (1966), Vercoquin et le Plancton (1946), L'écume des jours (1947), L'automne à Pékin (1947), L'Arrache-Cour (1953) y L'Herbe Rouge (1950).
} 
primer crítico ha focalizado en la presencia de las sensaciones en la obra de Vian. Sostiene que estas adquieren una dimensión existencial que se define en función del marco natural y cultural en el que se inscriben (Rybalka, 1968: 672). Señala, también, el lugar de privilegio que se atribuye a lo sensorial en los sujetos subalternos para la época, entre los que figuran las mujeres. Como comprobaremos, estarán fundamentalmente caracterizadas por las sensaciones olfativas, aunque se destacará, asimismo, lo visual. El análisis de Rybalka podría unirse al efectuado por Rolls, que aborda el tema de la ropa y, más específicamente, el valor de las medias de nylon y las joyas en la relación Francia-Estados Unidos. Es así que, desde la perspectiva visual, la descripción de las mujeres en los textos vianescos se reduce a rasgos físicos (como los ojos, cabellos, piel, senos y muslos), pero involucra también la vestimenta que, en ocasiones, despierta el erotismo o la sensualidad al ceñir el cuerpo femenino.

En el caso de L'automne à Pékin, del texto se desprende este tratamiento de la figura femenina. De manera general, Angel plantea la cuestión del olor de la mujer al pensar en el olor a nuevo de Rochelle cuando su amigo Anne la poseyó por primera vez. A esto añade que los hombres buscan el olor de la mujer a lo largo de todo su cuerpo (Vian, 1947: 187-188).

En cuanto a la descripción física de Rochelle y desde lo visual, Angel es el primero en detenerse en sus cabellos y ojos. Así, por ejemplo, se da cuenta de que cuando la conoció se quedó observándolos durante demasiado tiempo (Vian, 1947: 39). Además, encontraba difícil mirarla al rostro porque la joven brillaba demasiado. Sin embargo, Angel insiste en la necesidad de conocer el color de sus ojos (Vian, 1947: 40), que pocas páginas más tarde descubre azules (Vian, 1947: 48).

Por su parte, los senos y los muslos son los que, en cambio, ocupan un lugar predominante en la novela. Una vez muerto Anne, Rochelle invita a Angel a quedarse con ella, que, desnuda, ingresa en su cama. En este capítulo, que precisamente corresponde al epígrafe, se la describe con los pechos caídos y pesados, cubiertos por un blanco sujetador, y con carnosos muslos (Vian, 1947: 267). Se evidencia así la manera metonímica de referirse a la mujer, que es caracterizada a través de alusiones a su corporalidad fragmentada o mediante las percepciones sensoriales.

Igualmente, la ropa contribuye a marcar los atributos del cuerpo femenino. Rochelle, por ejemplo, consagra una parte de su tiempo a vestirse para partir al desierto de Exopotamia. El resultado, observa el narrador, era excepcional, ya que la abertura de su ligero abrigo de lana permitía atisbar un vestido verde tilo. Las piernas de la muchacha se insertaban apretadamente en un par de medias de nylon fino y zapatos de cuero salvaje (Vian, 1947: 86). Es así como, al cubrir los muslos femeninos, las medias se vuelven un elemento erótico.

En el capítulo VII del Deuxième Mouvement se encuentra una nueva alusión a los senos. Angel contempla el perfil de Rochelle, que llevaba puesto un jersey que resaltaba sus pezones, un poco postrados, aunque todavía excitantes (Vian, 1947: 183).

La lista de citas que encierran descripciones visuales y olfativas de la mujer resulta inagotable en la obra. No obstante, es en el último movimiento del capítulo IX donde la objetivación de la mujer alcanza su clímax. Ciertamente, Angel padece por no poder poseer a la mujer de su amigo. Sufre a lo largo del texto porque asiste al desmoronamiento del cuerpo de la joven, en tanto Anne goza de él. 
Continuamente se hace referencia al modo en que ella se gasta y su cuerpo acabará arrugado y marchito cuando la pareja termine la relación. Anne alude a la caducidad de su figura al asegurar que la joven se irá estropeando a una velocidad que aumentará en progresión geométrica (Vian, 1947: 151). Y en un momento en que Angel se encuentra sumido en sus cavilaciones respecto de esta situación, llega a plantear que Rochelle es una sale garce, desde cualquier perspectiva que se la considere. Agrega que sus pechos se encuentran cada vez más caídos y que Anne la va a exprimir como un limón, a dilatarla y reblandecerla. Sin embargo, segundos después, gira sus pensamientos 45 grados a babor para concluir en la inutilidad de construir frases obscenas contra una mujer que, bien considerada, «n'est, qu'un trou, du poil autor» (Vian, 1947: 187).

La mujer queda, por tanto, reducida únicamente a un objeto pasivo de sexualidad y esta consideración es puesta de manifiesto por Vian mediante una imagen de gran violencia, una metonimia que circunscribe el cuerpo femenino a una funcionalidad meramente sexual.

Al ser reducida a un objeto, la mujer carece de inteligencia. Sus «conocimientos», por el contrario, se limitan a la materia sexual. Rochelle es sujeto pasivo que se limita a las actividades receptivas. Así pues, en el capítulo 3 del Premier Mouvement, se afirma que Anne busca poner a Rochelle en situación de receptividad, para lo que la toma de la cabeza y coloca los labios sobre su mejilla. La joven resiste poco y durante poco tiempo (Vian, 1947: 90).

Asimismo, en la discusión que sostienen Anne y Angel, se hace hincapié en su utilidad. Angel increpa a su amigo destacando que no es necesario que se acueste con ella todas las noches. Y al recibir como respuesta que a ella le gusta, dubitativo, añade que a ella le gustaría con cualquiera (Vian, 1947: 148). En la misma conversación, Anne afirma categóricamente que, tanto en lo físico como en lo intelectual, no existe mujer indispensable. Resultan, incluso, cuadradas (Vian, 1947: 149), pues no tienen imaginación (Vian, 1947: 150). El diálogo concluirá en la misma línea. Anne interroga a Angel acerca de qué realizaría con Rochelle si la tuviera en su poder. Este último le responde que él no la destruiría, a diferencia de lo que está realizando Anne con la joven: ni siquiera la tocaría. Sostiene que únicamente la besaría y la colocaría desnuda sobre un lienzo blanco. Ante esta respuesta, Anne asegura que las mujeres, en su mayoría, ignoran que existen otras cosas (más que la sexualidad, según puede inferirse a partir del contexto) y que no se las puede culpar (Vian, 1947: 151)

El fruto de las meditaciones de dichos personajes se sintetiza, sin embargo, en el epígrafe misógino de Baudelaire que introduce el capítulo IX del último movimiento: "Aimer une femme intelligente est un plaisir de pédéraste» (Baudelaire en Vian, 2009: 261).

\section{3. Implosión del estereotipo femenino en $L$ 'automne à Pékin}

Desde una perspectiva teórica, tal como afirma Scott, todas las novelas vianescas juegan con las divisiones sociales (Scott, 1998: 19), no solo las que firmó con pseudónimo. En particular, el tema de la mujer es, sin lugar a duda, problemático en la Francia de las décadas 30 y 40, si aquello que se pretende abordar es exclusivamente la cuestión de la sexualidad. Siempre dentro de la búsqueda de 
estereotipos, Vian reduce a la mujer a la sexualidad y entra por tanto en el campo resbaloso -porque sus límites son constantemente desplazables- de la pornografía. Consideramos, entonces, que Vian desliza esta perspectiva de la mujer, desde un marco literario: no solo el implicado por las novelas negras (o «no serias»), sino también a lo largo de sus novelas autógrafas. Dicho marco se opone al ensayo, género utilizado por la élite intelectual contemporánea para abordar estas cuestiones.

No obstante, Vian no se limita a una representación estereotípica de la feminidad. Utilizará mecanismos implosivos, con los que buscará romperla desde su propio seno. El primero de ellos será la ambivalencia genérica, que se refleja en el personaje que se identifica en la novela con el falo, el representante textual de la masculinidad: Anne. En efecto, desde una perspectiva lingüística, su nombre constituye un patronímico femenino y ambivalente, que en la novela se utiliza para designar al hombre que goza continuamente del cuerpo de Rochelle.

Por otra parte, el carácter hiperbólico de la objetivación de la mujer resulta en una caricatura de la representación femenina: la mujer queda exclusivamente reducida a lo que de ella perciben los sentidos.

¿Qué valor encierra, entonces, este epígrafe en el que Vian cita a Baudelaire en alusión a la figura femenina? Para Baudelaire, la mujer, ser natural, conduce al hombre a los instintos más bajos y lo induce a una relación sádica a través del acto sexual. Si nos atenemos a la representación de la mujer en los textos vianescos, esta resulta un objeto sexual, hecho que se infiere de sus descripciones de los personajes de este género. Tanto el poeta maldito como Vian fueron acusados de misoginia. Sin embargo, más allá de sus particulares cosmovisiones, los dos escritores comparten una idea, que subyace a lo que expresamente postulan: la figura de la mujer constituye un pretexto, en tanto no es a la mujer en sí a la que critican. Por el contrario, la misoginia encubre un debate sobre la obra de arte en la modernidad para Baudelaire y una crítica de la sociedad en la que a Vian le tocó vivir y en la que la figura femenina es aún concebida de manera estereotipada.

\section{Bibliografía}

ARNAUD, Nöel (1990): Las vidas paralelas de Boris Vian. Barcelona, Versal.

AUSTIN, Lloyd James (1956): L'Univers poétique de Baudelaire: Symbolisme et Symbolique. París, Mercure de France.

BAudelaIRe, Charles (1908): Euvres posthumes. Ed. Théodore de Banville y Charles Asselineau. París, Mercure de France.

— (1975): Euvres Complètes. Ed. Claude Pichois. París, Gallimard, Bibliothèque de la Pléiade, 2 vols.

BLIN, Georges (1948): Le sadisme de Baudelaire. París, José Corti.

Compagnon, Antoine (2005): Les Antimodernes. París, Gallimard.

Clouzet, Jean (1976): Boris Vian. Madrid, Júcar. 
Duchateau, Jacques (1982): «Attention, romans piégés», Magazine littéraire, 182, pp. 30-32.

FERRAN, André (1933). L'Esthétique de Baudelaire. París, Hachette.

FlAUBERT, Gustave (2004): Diccionario de los lugares comunes. Buenos Aires, Del Zorzal.

GAUTIER, Théophile (1868): «Charles Baudelaire», en C. BAUdelaire, Les Fleurs du Mal. París, Michel Lévy Frères, pp. 1-75.

JuLliaRD, Claire (2007): Boris Vian. París, Gallimard.

RoLlS, Alistair (2005): «Silk or nylon: Boris Vian, leg fetishism and the American Wayé», Aumla, 103, pp. 93-108.

RYBALKA, Michel (1968): «Boris Vian et le monde sensible», The French Review, 41, pp. 669-674.

SANYAL, Debarati (2014): «Peindre, non la chose, mais l'effet qui la produite: défigurations du féminin dans "La femme sauvage et la petite-maîtresse"», en S. MurPHY, ed., Lectures du Spleen de Paris. Rennes, Presses Universitaires de Rennes.

SCHOOLCRAFT, Ralph (2009): «Vian, Sullivan: bon chic, mauvais genres», Europe, 967-968, pp. 6171.

ScotT, J. K. L. (1998): From dreams to despair. An integrated reading of the novels of Boris Vian. Amsterdam, Rodopi.

VIAN, Boris (1947): L'automne à Pékin. Lonrai, Les Éditions de Minuit, 2009. (1998): Écrits pornographiques. París, Christian Bourgois.

WiNOCK, Michel (1997): Le siècle des intellectuels. París, Seuil. 